\title{
Effects of Different Maternal Positions during Non-Stress Test on Maternofetal Physiological Parameters
}

Hend Abdallah EL Sayed: Lecturer of Obstetric and Woman Health Nursing, Faculty of Nursing, Benha University.

Shaimaa Hassan Mohamady Lecturer of Maternal and Newborn Health Nursing, Faculty of Nursing, Helwan University.

\begin{abstract}
Aim of the study to compare effects of different maternal positions during non-stress test on maternofetal physiological parameters. Setting: the current study was conducted at fetal monitoring room of obstetrics and gynecology department, Benha University hospital. Sample: A purposive sample of 72 women was recruited according to inclusion criteria. Three tools were used for data collection 1) A structured interview questionnaire. 2) Maternal-fetal physiological parameters sheet. 3) Visual analogue scale of maternal discomfort. Results: There were a highly statistically significant difference in maternal physiological parameters (systolic blood pressure, diastolic blood pressure, and pulse rate) in the three positions during the non-stress test $(\mathrm{p}=0.000)$. Number of accelerations and number of fetal movements in left lateral position was significantly higher than supine and semi fowler positions $(p=0.030)$ and $(p=0.133)$ respectively. Mean time taken for first fetal movement, and reactive non-stress test are significantly less in left lateral position compared to supine and semi fowler positions $(\mathrm{p}=0.000)$. Almost the studied women showed moderate variability in the three positions. A highly statistically significant difference regarding discomfort during non-stress test the three positions $(\mathrm{p}=0.000)$. Conclusion: The left lateral and semi-fowler positions during non-stress test demonstrated favorable maternofetal physiological parameters and women felt more comfortable than in supine position. The study recommended left lateral and semi-fowler positions can be encouraged as alternative positions during non-stress test.
\end{abstract}

Key Words: Fetal, Maternal, Parameters, Physiological, Positions, Non-stress test. 


\section{Introduction:}

The electronic evaluation of antenatal fetal heart rate pattern is a widely accepted screening test of fetal well-being. Nonstress test (NST) is often used as the first choice for fetal health and survival assessment Non-stress test still continues to be a valuable procedure for the assessment of fetal wellbeing at high-risk pregnancies ${ }^{[1,2]}$.

Non-stress test is based on the premise that the heart rate of a fetus is not acidotic or neurologically depressed will temporarily accelerate with fetal movement. Heart rate reactivity is thought to be a good indicator of normal fetal autonomic function. Loss of reactivity is most commonly associated with a fetal sleep cycle, but may result from any cause of central nervous system depression, including fetal academia ${ }^{[3]}$.

Furthermore, non-stress test is a noninvasive method that combines detection of fetal heart rate accelerations and presence of spontaneous or evoked fetal movement. NST is a relatively inexpensive procedure and has no known contraindications. NST is performed by nurses in a variety of settings including outpatient, inpatient, and home environment ${ }^{[4]}$.

Non-stress test can be reliably performed after 28 weeks gestation. In the healthy fetus with a functional central nervous system, fetal heart rate accelerations are reassuring finding related to fetal status ${ }^{[5]}$. The tracing of non-stress test is categorized as a reactive or nonreactive test. A reactive non-stress test shows the presence of two or more fetal heart rate accelerations of at least 15 beats per minute above the baseline fetal heart rate sustained for 15 seconds within a period of 20 minutes. It may be necessary to continue the tracing for 40 minutes accounts fetal sleep-wake cycles, because it may take this long for the healthy term fetus to display two fetal heart rate accelerations. If after 40 minutes the criteria are not met, the test is considered or nonreactive ${ }^{[6]}$.

Nurses play an important role in non-stress test; prior to the NST, explain the testing procedure and asked woman to empty bladder. Place the woman in the appropriate position and apply the two external monitor belts. Document the date and time of test, the reason for testing, and maternal vital signs. Obtain a baseline fetal monitor strip over 15 to 30 minutes. During the test, observe for signs of fetal activity with a concurrent acceleration of the fetal heart rate. Interpret the NST as a reactive or nonreactive. After NST 
procedure, assist the woman off the table. The results are discussed with the woman by the health care provider. Provide teaching about warning signs and symptoms. If serial NSTs are being done, schedule the next testing sessions ${ }^{[7]}$.

\section{Significance of the study:}

In last trimester of pregnancy non-stress test is a part of prenatal diagnosis to monitoring fetal wellbeing. Through clinical experience, the researchers found that in most hospitals, pregnant women are generally positioned in the supine position for non-stress testing, because this position allows easy application of the test. However, supine position causes aortocaval compression which decreases blood supply to the fetus leading to nonreactive results. Hence, position is one of the main factors to be considered during non-stress testing where proper maternal position eliminates procedure related errors and prevent false interpretation. Thus, the current study is undertaken to compare the effects of different maternal positions during non-stress test on maternofetal physiological parameters.

\section{Aim of the study:}

The present study aimed to compare the effects of different maternal positions during non-stress test on maternofetal physiological parameters.

\section{The study hypotheses:}

Left lateral and semi-fowler maternal positions during non-stress test showed better maternal and fetal physiological parameters than supine position.

Left lateral and semi-fowler maternal positions during non-stress test were more comfortable than supine position.

\section{Subjects and Methods}

\section{Study design:}

Quasi -experimental design was used for this study.

\section{Setting:}

The study was conducted in fetal monitoring room at obstetrics and gynecology department, Benha University hospital.

\section{Sample:}

Type and size: A purposive sample of 72 pregnant women attending predetermined setting was recruited in the study.

Technique: Eighty-six women were eligible for the study according to inclusion criteria at time of data collection. Six women refused to recruit the study. The reason for refusal was not having time to complete the study procedure. The final sample consisted of eighty women (72 sample size plus 8 pilot study).

Inclusion criteria: Pregnant women with singleton pregnancies, gestational age 3242 weeks, primigravidae or multigravidae 
with intact amniotic membranes attending for NST monitoring during the antenatal check-up, and willing to participate in the study.

Exclusion criteria: Pregnant women in labor, multiple gestations, had any medical diseases (such as severe hypertension, eclampsia and heart disease), ruptured membranes, intrauterine growth retardation and intrauterine fetal death.

\section{Tools for data collection:}

Three tools for data collection as follows:

\section{Tool I: A structured interviewing} questionnaire included general characteristics of study sample such as age, educational level, occupation, residence, and food intake prior non-stress test. Obstetric history included gravidity, gestational age, and indications of nonstress testing.

\section{Tool II: Maternal-fetal physiological} parameters sheet, this tool was designed by the researchers and composed of two parts:

Part (1): Maternal physiological parameters included pulse rate, respiratory rate, systolic and diastolic blood pressures. Part (2): Fetal physiological parameters included baseline fetal heart rate, number of accelerations, time taken for first fetal movement, a number of fetal movements; time is taken for reactive NST, reactivity of NST and variability.

\section{Interpretation of fetal parameters:}

Based on the National Institute of Child Health and Human Development ${ }^{[8]}$.

Baseline heartbeat is defined as the mean of heartbeats in 10 minutes after rounding more than 5 beat/minute increases.

Variability is defined as change in fetal heartbeat for 2 cycles in a minute. Variability is determined as the distance between the minimum (0) and maximum (25) number of heartbeats. Accordingly: Lack of variability: The distance is not measurable. Mild variability: The distance is measurable to $\leq 5$ beat $/$ minute. Average variability: The distance is 6-25 beat/minute. Severe variability: The distance is $>25$ beat $/$ minute.

Acceleration is defined as a sudden, detectable above 15 beat/minute or more in fetal heartbeat lasting for more than 15 seconds.

Reactive: Two or more FHR acceleration of 15 beat/minute lasting 15 seconds in 20 minute.

Non-reactive: any tracing with no FHR acceleration or inadequate acceleration that is less than 15 beat/minute. 


\section{Tool III: Visual analogue scale of} maternal discomfort:

The visual analogue scale of maternal discomfort was adopted from ${ }^{[9]}$. to assess the intensity of the discomfort. It consists of a $10 \mathrm{~cm}$ horizontal scale with verbal descriptors. The descriptors "no discomfort' corresponds to ' 0 ' on the extreme left and 'severe' corresponds to ' 10 ' on the extreme right. Participants were asked to put a mark on the $10 \mathrm{~cm}$ line at a point that corresponds to level of discomfort in the three positions (supine, semi fowler, and left lateral). At this scale, the classification of discomfort was done according to the scores of discomfort (no discomfort: 0 , mild: $1<4$, moderate: $4<7$, severe: 7-10).

\section{Tools validity and reliability:}

The tools of data collection were reviewed for comprehensiveness, appropriateness by a panel of three experts of maternal health nursing and obstetrics medicine. The panel ascertained the validity content of the tools. The reliability was done by Cronbach's Alpha coefficient test which revealed the three tools consisted of relatively homogenous items as indicated by the moderate to high reliability of each tool. The internal consistency of maternalfetal physiological parameters sheet was $\alpha$
0.73, and visual analogue maternal discomfort scale was $\alpha 0.75$.

\section{Ethical considerations:}

An explanation of the study aim and process were given to women, oral consent was obtained from each woman, strict confidentiality was ensured for any obtained information. Each woman was informed that the study do not entail any harmful effect on her health and fetus, participation is voluntary. Withdrawal from the study at any time is allowed without any effect on the care provided.

\section{Pilot study:}

The pilot study was carried out on ten percent of the total sample ( 8 women) to ascertain the relevance, clarity, applicability of the tools, and to detect any problems peculiar to study conduct. Also, the pilot study helped to estimate the time needed to complete the questionnaires. According to the results of the pilot study, modifications were done such as adding question about food intake prior non-stress test. Women involved the pilot study were excluded in the main study sample.

\section{Field work:}

The study was carried out from the beginning of September 2014 to the end of November 2014. Official approval was obtained from Dean of Faculty of Nursing 
to Director of Benha University Hospital. The researchers attended the previously mentioned setting three days per week from 9.00 a.m until 2.00 p.m.

The study purpose and procedure were explained to every woman and an oral consent to participate in the study was obtained. The interview was conducted individually. The researchers instructed women that no need for oral intake of food or drinks during the testing. Afterward, the general characteristics of studied sample were collected through a structured interviewing questionnaire.

For maternal physiological parameters, brachial blood pressure was assessed in the woman's dependent arm, using an automatic cuff. This assessment was performed at least 5 minutes after assumption of the randomized study position to allow hemodynamic equilibrium to occur. In addition, maternal pulse and respiration are assessed in the three positions supine, semi fowler, and left lateral.

For fetal physiological parameters, the researchers perform an abdominal examination to detect the quadrant of the maternal abdomen corresponding to the fetal back for location maximum tone of fetal heart sound. Ultrasonic gel was applied to the transducer connected to
NST machine, and placed on the selected site of fetal heart sound. The transducer was strapped snugly on the woman. The recording was done initially with the woman in the supine position as per hospital protocol followed after 10 minutes by left lateral position and lastly after 10 minutes followed by a semi-fowler position with angle 45 -degree. If signal is lost due to fetal and or maternal movement, the transducer was readjusted until a good tracing was obtained. Fetal movement was marked by the woman by pressing the remoter switch. Recording time was 20 minute for every position. NST Graph was observed for baseline heart rate, number of accelerations, time is taken for first fetal movement, a number of fetal movements, reactive NST and variability.

After completion of non-stress test, the women were asked to rate their discomfort at the three positions by using visual analogue scale.

\section{Limitation of the study:}

The researchers faced some resistances from some obstetricians during performing non-stress test, because the study procedure took a long time.

\section{Statistical analysis:}

Data entry and analysis were done using the Statistical Package for Social Sciences 
(SPSS version 20.0) followed by tabulation. Descriptive statistics were applied (mean, standard deviation, frequency, and percentages). Test of significance (Chi-square test, Fisher Exact Test, and ANOVA test) were used to test the study hypothesis. A statistically significant difference was considered at $p$ $\leq 0.05$, and a highly statistically significant difference was considered at $\mathrm{p} \leq 0.001$.

\section{Results:}

Table (1) shows that, $68 \%$ of studied women were in the age group 21-25 years with mean age $24.84 \pm 1.16$ years. $59.7 \%$ had secondary educational level, whereas only $11.1 \%$ of women can read and write. Regarding occupation, $63.9 \%$ of the women were working. As regards residence, $58.3 \%$ of women were living in rural areas. $79.2 \%$ of women had food intake more than two hours prior nonstress test.

Table (2) depicts that, $70.8 \%$ of women were primigravidae, the mean gestational age of the study women was $37.74 \pm 1.99$ weeks. As regards indications of nonstress test, $52.8 \%$ of the studied women had decreased fetal movement, $22.2 \%$ had gestational diabetes, $13.9 \%$ had pregnancy induced hypertension and $11.1 \%$ had $\mathrm{Rh}-$ ve incompatibility.
Table (3) reveals a highly statistically significant difference in maternal physiological parameters (systolic blood pressure, diastolic blood pressure and pulse rate) in the three positions during the non-stress test $(\mathrm{p}=0.000)$. In supine, semi fowlers, and left lateral positions, mean systolic blood pressure was $100.43 \pm 8.30$, $115.54 \pm 3.99$ and $117.15 \pm 4.69 \mathrm{mmHg}$ respectively. Mean diastolic blood pressure was $64.48 \pm 3.79,75.93 \pm 3.44$, and $77.38 \pm 2.76 \mathrm{mmHg}$ respectively. Mean pulse rate in supine position was $69.63 \pm 5.05$ beats/min while in semifowler position was $86.26 \pm 9.10$ beats $/ \mathrm{min}$ and left lateral position was $79.81 \pm 2.63$ beats/min. Meanwhile, there was no statistically significant difference regarding respiratory rate among the three positions $(\mathrm{p}=0.923)$.

Table (4) shows a highly statistically significant difference in baseline fetal heart rate between supine, semi-fowler and left lateral positions $(\mathrm{p}=0.000)$. The mean baseline fetal heart rate was $134.28 \pm 5.66$, $137.12 \pm 0.78$ and $140.32 \pm 3.26$ beat/minute respectively. Number of accelerations in left lateral position was significantly higher $5.48 \pm 1.07$ than supine and semi-fowler positions $4.97 \pm$ 1.17 and $5.14 \pm 1.27$ respectively 
$(\mathrm{p}=0.030)$. Regarding mean time taken for first fetal movement, and reactive nonstress test are significantly less in left lateral position compared to supine and semi-fowler positions( $\mathrm{p}=0.000$ ). mean number of fetal movements was higher in left lateral position $5.88 \pm 2.14$ than supine and semi-fowler $5.29 \pm 1.61$, and $5.76 \pm 1.83$ respectively with no statistically significant difference $(\mathrm{p}=0.133)$.

Figure (1) shows that the fetal reactivity was changed according to the maternal position, $87.5 \%$ had reactive in left lateral position, $66.7 \%$ reactive in semi-fowler position, and $51.4 \%$ in a supine position $(\mathrm{P}=0.000)$.

Figure (2) reveals that almost the studied women showed moderate variability in the three positions.

Figure (3) illustrates that $65.3 \%$ of the studied women during non-stress test reported severe discomfort women in supine position compared to $0.0 \%$ and $7.8 \%$ in left lateral and semi-fowler positions respectively $(\mathrm{p} \leq 0.000)$.

Table (1) Distribution of the studied women according to their general characteristics (n=72)

\begin{tabular}{|c|c|c|}
\hline Variables & No & $\%$ \\
\hline \multicolumn{3}{|l|}{ Age (years): } \\
\hline$\leq 20$ & 1 & 1.4 \\
\hline $21-25$ & 49 & 68.0 \\
\hline $26-30$ & 22 & 30.6 \\
\hline Mean \pm SD & \multicolumn{2}{|c|}{$24.84 \pm 1.16$} \\
\hline \multicolumn{3}{|l|}{ Level of education : } \\
\hline Read and write & 8 & 11.1 \\
\hline Primary education & 12 & 16.7 \\
\hline Secondary education & 443 & (59.7 \\
\hline University education & 9 & 12.5 \\
\hline \multicolumn{3}{|l|}{ Occupation : } \\
\hline Working & 46 & 63.9 \\
\hline Housewife & 26 & 36.1 \\
\hline \multicolumn{3}{|l|}{ Residence : } \\
\hline Urban & 30 & 41.7 \\
\hline Rural & 42 & 58.3 \\
\hline \multicolumn{3}{|c|}{ Food intake prior non-stress test: } \\
\hline Less than one hour & 5 & 6.9 \\
\hline 1-2 hours & 10 & 13.9 \\
\hline More than two hours & 57 & 79.2 \\
\hline
\end{tabular}


Table (2) Distribution of the studied women according to obstetric history $(n=72)$

\begin{tabular}{|c|c|c|}
\hline Variables & No & $\%$ \\
\hline \multicolumn{3}{|l|}{ Gravidity : } \\
\hline Primigravidae & 51 & 70.8 \\
\hline Multigravidae & 21 & 29.2 \\
\hline \multicolumn{3}{|l|}{ Gestational age (weeks): } \\
\hline $32-35$ & 9 & 12.5 \\
\hline $36-38$ & 40 & 55.5 \\
\hline $39-42$ & 23 & 32.0 \\
\hline Mean \pm SD & \multicolumn{2}{|c|}{$37.74 \pm 1.99$} \\
\hline \multicolumn{3}{|l|}{ Indications of non-stress testing: } \\
\hline Decreased fetal movement & 38 & 52.8 \\
\hline Gestational diabetes & 16 & 22.2 \\
\hline Pregnancy induced hypertension & 10 & 13.9 \\
\hline Rh -ve incompatibility & 8 & 11.1 \\
\hline
\end{tabular}

Table (3) Comparison of the maternal physiological parameters between supine, semifowler and left lateral positions $(n=72)$.

\begin{tabular}{|c|c|c|c|c|c|}
\hline \multirow{2}{*}{$\begin{array}{c}\text { Maternal } \\
\text { Physiological } \\
\text { parameters }\end{array}$} & $\begin{array}{c}\text { Supine } \\
\text { Position } \\
n=72\end{array}$ & $\begin{array}{c}\text { Semi Fowler } \\
\text { Position } \\
n=72\end{array}$ & $\begin{array}{c}\text { Left lateral } \\
\text { Position } \\
n=72\end{array}$ & \multirow[t]{2}{*}{$F$} & \multirow[t]{2}{*}{ P-value } \\
\hline & Mean \pm SD & Mean \pm SD & Mean \pm SD & & \\
\hline $\begin{array}{ll}\text { Blood } & \text { pressure } \\
(\mathrm{mmHg}) & \end{array}$ & & & & & \\
\hline Systolic & $100.43 \pm 8.30$ & $115.54 \pm 3.99$ & $117.15 \pm 4.69$ & 171.785 & $0.000 * *$ \\
\hline Diastolic & $64.48 \pm 3.79$ & $75.93 \pm 3.44$ & $77.38 \pm 2.76$ & 318.030 & $0.000 * *$ \\
\hline Pulse rate (beat/min). & $69.63 \pm 5.05$ & $86.26 \pm 9.10$ & $79.81 \pm 2.63$ & 131.481 & $0.000 * *$ \\
\hline $\begin{array}{l}\text { Respiratory rate } \\
\text { (cycle/min). }\end{array}$ & $21.36 \pm 0.48$ & $21.33 \pm 0.47$ & $21.36 \pm 0.48$ & 0.080 & 0.923 \\
\hline
\end{tabular}

**A highly statistically significant difference 
Table (4) Comparisons of fetal physiological parameters during non-stress test in supine, semi-fowler and left lateral positions $(n=72)$.

\begin{tabular}{|c|c|c|c|c|c|}
\hline \multirow[t]{2}{*}{$\begin{array}{l}\text { Fetal physiological } \\
\text { parameters }\end{array}$} & $\begin{array}{c}\text { Supine } \\
\text { Position } \\
n=72\end{array}$ & $\begin{array}{l}\text { Semi Fowler } \\
\text { Position } \\
n=72\end{array}$ & $\begin{array}{c}\text { Left lateral } \\
\text { Position } \\
n=72\end{array}$ & \multirow[t]{2}{*}{$\mathbf{F}$} & \multirow[t]{2}{*}{ P-value } \\
\hline & Mean \pm SD & Mean \pm SD & Mean \pm SD & & \\
\hline $\begin{array}{l}\text { Baseline fetal heart rate } \\
\text { (beat/minute). }\end{array}$ & $\begin{array}{c}134.28 \pm \\
5.66\end{array}$ & $\begin{array}{c}137.12 \pm \\
0.78\end{array}$ & $\begin{array}{c}140.32 \pm \\
3.26\end{array}$ & 45.54 & "0.000** \\
\hline Number of accelerations & $4.97 \pm 1.17$ & $5.14 \pm 1.27$ & $5.48 \pm 1.07$ & 3.57 & $0.030 *$ \\
\hline $\begin{array}{l}\text { Time taken for first fetal } \\
\text { movement (minutes). }\end{array}$ & $7.75 \pm 1.32$ & $7.19 \pm 1.64$ & $6.31 \pm 2.12$ & 12.76 & $0.000 * *$ \\
\hline $\begin{array}{l}\text { Number of fetal } \\
\text { movements. }\end{array}$ & $5.29 \pm 1.61$ & $5.76 \pm 1.83$ & $5.88 \pm 2.14$ & 2.04 & 0.133 \\
\hline $\begin{array}{l}\text { Time taken for reactive } \\
\text { non-stress test (minutes). }\end{array}$ & $15.15 \pm 1.77$ & $13.40 \pm 1.51$ & $10.27 \pm 2.51$ & 39.025 & $0.000 * *$ \\
\hline
\end{tabular}

*A statistically significant difference

$* *$ A highly statistically significant difference

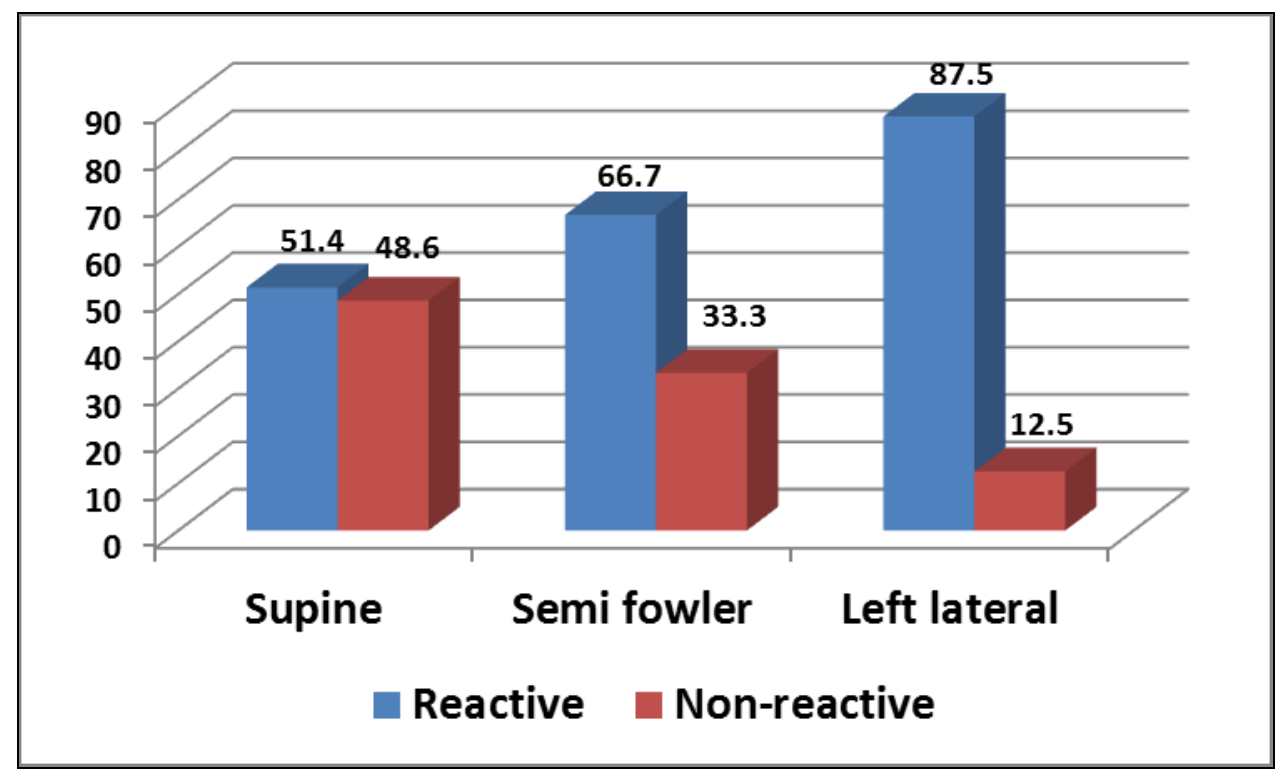

$$
\mathrm{X}^{2}=21.93 \mathrm{P}=0.000 * *
$$

Figure (1): Percentage distribution of the studied women according to fetal reactivity $(n=72)$. 


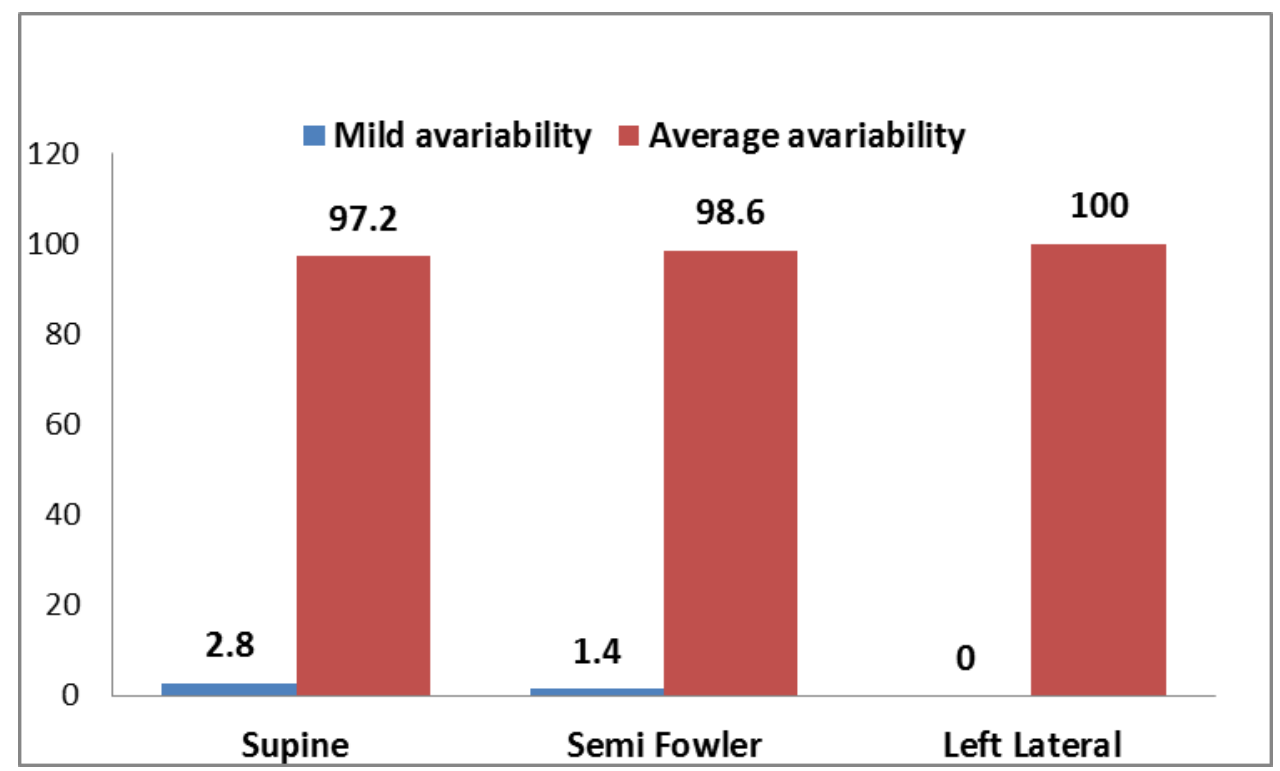

Figure (2): Percentage distribution of the studied women according to fetal variability $(\mathbf{n}=72)$.

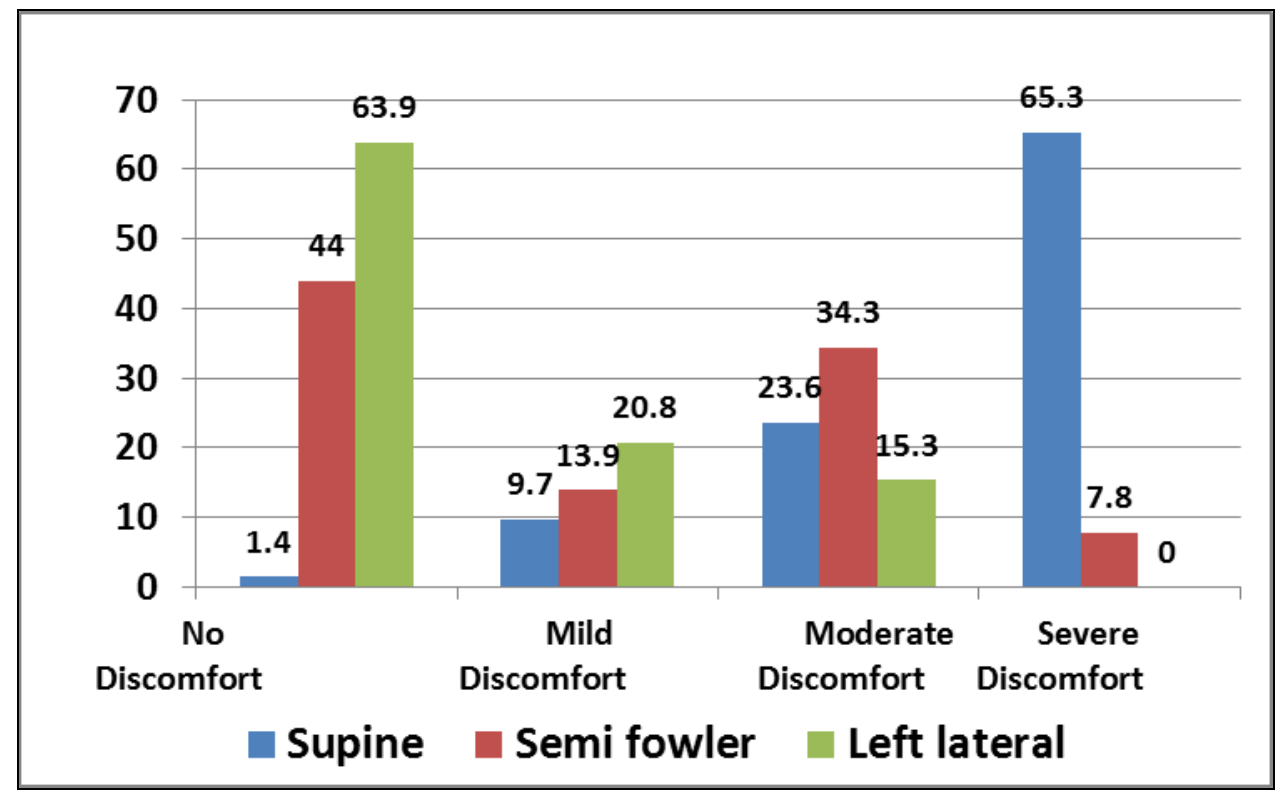

FET $\mathrm{P}=0.000 * *$

Figure (3): Percentage distribution of the studied women according to their discomfort level during non-stress test in supine, semi-fowler and left lateral positions $(n=72)$. 


\section{Discussion}

The present study aimed to compare the effects of different maternal positions during non-stress test on maternofetal physiological parameters. The finding of the present study showed that more than two-thirds of the studied women were in the age group 21-25 years with mean age $24.84 \pm 1.16$ years. This finding is in agreement with Lohana et al., ${ }^{[10]}$ who reported that the mean age in pregnant women performing non-stress test at 37 to 42 weeks of gestation was $24.18 \pm 3.25$ years. Also, Riahin et al., ${ }^{[11]}$ found that the mean age of the participants during non-stress test was $24.7 \pm 5.2$ years. In addition, the present study finding showed that more than three-quarters of the women had a food intake more than two hours prior the non-stress test. This is similar to Samuel et al., ${ }^{[12]}$ mentioned that $77.3 \%$ had food intake less than two hours before the test.

Regarding obstetric history, the findings of the present study illustrated that less than three quarters of women were primigravidae, the mean gestational age of the study women was $37.74 \pm 1.99$ weeks. As regards indications of non-stress test, more than half of the studied women had decreased fetal movement. These findings are disagreed with Kaur and Saha [13] who reported that $54 \%$ of antenatal mothers were primigravidae. Period of gestation 33\% were having 32-35 weeks of gestation, $40 \%$ were having 36-38 weeks of gestation and $27 \%$ were having 39-41 weeks of gestation.

On investigating maternal physiological parameters, the findings of the current study revealed a highly statistically significant difference in maternal systolic blood pressure, diastolic blood pressure and pulse rate in the three positions during the non-stress test. Blood pressure and pulse rate in left lateral and semi-fowler positions were more favorable and within normal range than in the supine position. However, there was no statistically significant difference in maternal respiration rate in the three positions during the test. This is related to the fact that the enlarged uterus of late pregnancy can compress the inferior vena cava when a woman lies in a supine position, resulting in decreased blood pressure. Positioning a pregnant woman in left lateral or semi-fowler positions during non-stress test can alleviate symptoms of aortocaval compression, hemodynamic alteration in brachial blood pressure and heart rate within normal values. 
These findings were supported by Tamas et al., ${ }^{[14]}$ who found that non-stress test parameters were correlated with maternal hemodynamic indices and alert fetal heart rate patterns that change with different maternal positions. Additionally, Esin [15] recommended that lateral recumbent or sitting positions may be more acceptable for the pregnant women after 32 gestational weeks to avoid supine hypotension or maternal and possibly fetal discomfort. In contrast, Maneesha [9], found no significant difference in the maternal physiological parameters (pulse, respiration, systolic and diastolic pressure) in the supine, left lateral and semi-sitting positions during the non-stress test $(\mathrm{p}>0.05)$.

Concerning fetal physiological parameters during a non-stress test, there was a significant difference in baseline fetal heart rate between supine, semi-fowler and left lateral positions. However, the baseline fetal heart rate varies significantly with left lateral and semi-fowler positions compared to the supine position, all the studied women had a normal baseline heart rate. This is due to fact changes in maternal position, possibly evoking a response in fetal heart rate. In supine position, the pressure on the inferior vena cava and pelvic veins of enlarged uterus causes a decrease in venous return and leading to less placental perfusion and lower fetal heart rate. This finding is supported by Pandey and Magon, [16] mentioned that the baseline fetal heart rate should be within the normal range of 110 to 160 beats/minute.

Moreover, number of accelerations was significantly higher in left lateral position than semi-fowler and supine positions. The mean time taken for first fetal movement and reactive non-stress test is significantly less in left lateral position compared to supine and semi-fowler positions. The mean number of fetal movements perceived by women in left lateral position was higher than supine and semi-fowler with no statistically significant difference. In addition, left lateral position was associated with more fetal reactivity than semi-fowler and supine positions. These findings may be due to supine position causes aortocaval compressions that affect maternal hemodynamic indices that cause redistribution of blood flow and nonreactive fetal heart rate. Meanwhile, left lateral and semi-fowler positions optimize uteroplacental perfusion and fetal heart rate patterns.

These findings are in accordance with Aluş et al., ${ }^{[17]}$ who reported that supine position showed less fetal reactivity than 
lateral position $(\mathrm{p}=0.01)$ and required more time to achieve reactivity $(p=0.02)$, they concluded that supine position causes lowest non-reactivity with physical discomfort. Also, Cabaniss and Ross ${ }^{[18]}$ pointed out that NST in lateral position may be rewarded with fetal accelerations, as uteroplacental circulation may be increased. Sekhavat and Tabatabaei, [19] added that supine position showed less fetal reactivity and required more time to achieve reactivity than left lateral position, the average time required to demonstrate a reactive NST was 10.62 minutes in lateral and 15.48 minutes in the supine position.

In relation to a comfortable position during non-stress test, the finding of the current study revealed that about two-thirds of the studied women felt severe discomfort in supine position compared to left lateral and semi fowler positions. This may attributed to women during NST suffered from shortness of breathing and backache in supine position secondary to pressure of gravid uterus. This finding is consistent with Sekhavat and Tabatabaei ${ }^{[19]}$ who found that $16.43 \%$ of women were uncomfortable in lateral position during NST compared to $67.86 \%$ in supine position. As well, Kaur and Saha [13] reported that more than half of antenatal women $65 \%$ reported to be comfortable in left lateral position during the non-stress test, whereas only one-fourth of them supported sitting position and $10 \%$ were comfortable in both positions.

\section{Conclusion:}

The left lateral and semi-fowler positions adopted for non-stress test by the antenatal women during the third trimester demonstrated favorable maternofetal physiological parameters. As well as, antenatal women are more comfortable than in supine position. Thus, the study hypotheses were supported.

\section{Recommendations:}

Left lateral positions and semi-fowler can be encouraged as alternative positions during non-stress test.

The preference of the pregnant women position should be determined before nonstress test technique to minimize discomfort.

The study can be replicated on a larger sample for generalizing the findings.

Further studies:

Designing health training programs regarding protocol for non-stress test to healthcare providers especially staff nurses.

\section{References}

1. Oyelese, Y., and Vintzileos, A.The uses and limitations of the fetal 
biophysical profile. Clin. Perinatol 2011; 38(1): 47-64.

2. Verma, A., and Shrimali, L. Impact of admission non-stress test as a screening procedure on perinatal outcome. International Journal of Medical and Pharmaceutical Science 2012; 3(5): 6-10.

3. American College of Obstetricians and Gynecologists (2014): Antepartum fetal surveillance. Practice Bulletin No. 145. Obstet Gynecol 2014; 124 (1):182-92.

4. Littleton-Gibbs, L.Y., and Engebretson, J.C. Maternity nursing care, $2^{\text {nd }}$ ed., Delmar, Cengage Learning, USA., 2013;446.

5. Miller, L.A., Miller,D.A., and Tucker, S.M. Mosby's pocket guide to fetal monitoring: A multidisciplinary approach, $7^{\text {th }}$ ed., St Louis,Mosby Co., 2013; 364.

6. Cunningham, G., Leveno. K., Bloom.S., Hauth., J, Rouse.D., Spong. C., (2014): Antepartum Assessment, Williams Obstetrics, $24^{\text {th }}$ ed. New York: McGraw Hill; 3014; 407-422.

7. Ricci, S., Kyle, T., and Carman, S. Maternity and pediatric nursing, $2^{\text {nd }}$ ed., Lippincott Williams and Wilkins, Philadelphia, 2012; 332.
8. Cunningham, G., Leveno. K., Bloom.S., Hauth, J., Rouse.D., Spong C. Antepartum Assessment, Williams Obstetrics, $23^{\text {th }}$ ed. New York: McGraw Hill 2010;34-348.

9. Maneesha, M.S. Study to assess the effect of maternal positions on physical and physiological parameters of antenatal mothers and fetus during non-stress test in a selected hospital at kollam(dist),Kerala. Nepal Journal of Epidemiology 2013; 3(4):256, available at www.nepjol.info/index.php/NJE.

10. Lohana, R., Khatri, M., and Hariharan, C. Correlation of nonstress test with fetal outcome in term pregnancy (37-42 Weeks), Int $\mathbf{J}$ Reprod Contracept Obstet Gynecol.2013; 2(4): 639-645.

11. Riahin, A., Lorzade, N., Suri, A., Gharehbeglou, M., Rasuli, A., Torkamani, A., Fadavi, Z.S., Hatami, S., and Mahmudi, F. The diagnostic value of non-stress test in patients with decreased amniotic fluid index and decreases fetal movements. Int Elec J Med.2013; 2(1):22-26.

12. Samuel, R., Karkada, S., Fernandes, S., and Bhat, P. Materno fetal physiological parameters in sitting and left lateral position during 
non-stress test monitoring in pregnancy: A cross-over study, Manipal Journal of Nursing and Health Sciences, 2015;1(2): 83- 86.

13. Kaur, V.S., and Saha, P. K., (2015): A comparative study to assess the effect of different maternal position on reactivity and time consumption for non-stress test, Nursing and Midwifery Research Journal 2015; 11(4): 145-152.

14. Tamas, P., Szilagyi, A., and Jeges, S. Effects of maternal central hemodynamic on fetal heart rate patterns. Acta Obstet Gynecol Scand.2007; 86(6):711-804.

15. Esin, S. Factors that increase reactivity during fetal non-stress testing, Curr Opin Obstet Gynecol.2014;269(1):61-66.

16. Pandey, A., and Magon, N. Screening in Obstetrics and Gynecology management of abnormality, Jaypee Brothers Medical Publishers, New Delhi3 2015;102.

17. Alus, M., Okumus, H., Mete, S., and Guclu. S. The effects of different maternal positions on non-stress test: An experimental study. Journal of Clinical Nurse 2007; 16(3):562-568.
18. Cabaniss, M. L., and Ross, M. G. Fetal monitoring interpretation, $2^{\text {nd }}$ ed., Lippincott Williams and Wilkins, Philadelphia, 2010;265.

19. Sekhavat, L., and Tabatabaei, A.The effect of different maternal position on non-stress test (NST). World Applied Science Journal 2010; 32 (5):838-856. 